\title{
Occurrence of Antibiotic Resistant Bacteria in Environmental Wastes
}

\author{
R.C. Poudel ${ }^{1 *}$, D.R. Joshi ${ }^{2}$, N.R. Dhakal ${ }^{3}$ and A.B. Karki ${ }^{4}$ \\ ${ }^{1}$ National College, Khusubi, Kathmandu \\ ${ }^{2}$ Central Department of Microbiology, Kirtipur, Kathmandu \\ ${ }^{3}$ Alternative Energy Promotion Centre, Khumaltar, Lalitpur \\ ${ }^{4}$ Biogas Sector Partnership (BSP), Nepal \\ E-mail: ramchpd5@yahoo.com
}

Received: 21.01.2009, Accepted: 09.04.2009

\begin{abstract}
Microbial resistance to antibiotics has been emerging in environmental isolates. This study was carried out from October 2008 to January 2009 to describe the antibiotic susceptibility pattern of the bacteria isolated from sewage sludge, biowaste and bioslurry samples. A total of 49 identified isolates were taken for antibiotic susceptibility test. Amikacin and Gentamic in were the effective antibiotics for the Gram negative bacteria, comparatively Escherichia coli was the most sensitive. Similarly, all isolates of Staphylococcus aureus and Enterococcus spp. were sensitive to Tetracycline and Erythromycin respectively and none of these isolates were resistant to Vancomycin. Out of 13 S. aureus, five (38.5\%) were Methicillin resistant Staphylococcus aureus (MRSA). The multidrug resistant (MDR) isolates accounted for $46.9 \%$, the highest percentage of MDR isolates was seen in Pseudomonas aeruginosa (9/12, 75.0\%). The proper management of multidrug resistant bacteria present in waste is suggestive for environmental and public health.
\end{abstract}

Key words: Multidrug resistant bacteria, Bio-waste, Sewage sludge, Bioslurry

\section{Introduction}

Sewage sludge and biowaste contain human and animal pathogens in high number (Lepeuple et al., 2004). The prophylactic treatments, such as medication and sanitation, can help to control the pathogens but these treatments are increasingly expensive and decreasingly effective since drug resistance can develop in microorganisms (Marchaim, 2007). Antibiotic resistant bacteria are now found in large numbers in virtually every ecosystem.

Resistance against antimicrobials may cause severe problems in human and animal healthcare (Sahlström, 2006). The development of bacterial antimicrobial resistance is neither an unexpected nor a new phenomenon. The consequences of over use of antibiotics in human, animal and agriculture exposes both terrestrial and aquatic environments which accelerate for the development of drug resistant bacteria in the environment and also change the community structure/diversity of environmental bacteria (Andersson, 2003; Food Safety, 2008). Due to the application of manure from medicated livestock being applied to agricultural soils, multiple drug 
resistance has developed in the micro-flora and intestinal flora of livestock (HallingSorensen et al., 1998). Besides antimicrobial substances, the non-antibiotic substances that are frequently found in sewage such as disinfectants, sterialints, and heavy metals increase selective pressure on microorganisms to develop resistance to these agents (Baquero et al., 1998).

The presence of large quantities of specific antibiotics in the environment, the disposal of unused drugs and the use of antibiotics in raising food animals has contributed significantly to the global pool of antibiotic resistant bacteria among human, animal and the environment and thus create a serious global human and animal health problem. We designed a study to describe antibiotic susceptibility pattern of the gram positive and gram negative bacterial isolates from waste samples in the environment.

\section{Materials and methods}

A total of 36 waste samples including a sewage sludge, seventeen different biowaste and eighteen bio-slurry samples were selected for the isolation of gram positive and gram negative bacteria. Sewage sludge was collected from sewerage treatment plant at Guheshwori in Kathmandu whereas biowaste (fruit and vegetable waste, poultry manure, animal dung, kitchen waste etc.) and bioslurry (digested residue) samples were collected from different institutional and household biogas plants within Kathmandu valley. All the samples were collected by random sampling technique and were analysed in Microbiology Laboratory of National College, Kathmandu. Different microbiological media were used for the isolation of different bacteria which were identified by their cultural, morphological and biochemical characteristics.

Altogether 49 bacterial isolates were subjected to antibiotic susceptibility testing by using a disc diffusion method in accordance with Clinical and Laboratory Standards Institute (CLSI). Staphylococcus aureus producing inhibition less than 10 $\mathrm{mm}$ zone diameter or producing no inhibition to Oxacillin discs $(1 \mu \mathrm{g})$ were considered resistant to Oxacillin and the organism was defined as MRSA (MH, 2002; Savas et al., 2005). On the basis of sensitivity pattern of the isolates, bacteria that were resistant to $\geq 2$ classes of antibiotics were considered as multi drug resistant bacteria (Dahal et al., 2005).

\section{Results}

A total of 49 bacterial isolates were identified which belong to five genera and their pattern of distribution is shown in Figure 1.

Gram negative bacteria exhibited elevated resistance towards Amoxycillin. All isolates of Escherichia coli were sensitive to Gentamicin and Amikacin. The most effective antibiotics for Pseudomonas aeruginosa were found to be Gentamicin and Amikacin as 11(91.67\%) isolates were sensitive. Similarly, out of 5 Salmonella spp., 4 (80\%) were sensitive to Ciprofloxacin, Cotrimoxazole, Chloramphenicol and Gentamicin (Table 1). The antibiotic susceptibility test for Staphylococcus aureus showed that Vancomycin and Tetracycline was the most effective as all $13(100 \%)$ isolates were sensitive. Out of 13 isolates, 5(38.46\%) 
isolates were found to be MRSA. All Enterococcus spp. were sensitive be Vancomycin and Erythromycin and resistant to Cephalexin and Ceftazidime (Table 2). Out of 49 isolates taken for antibiotic susceptibility test, 23 (46.9\%) were found to be MDR isolates. The results are shown in Table 3.

\section{Discussion}

Sewage sludge and biowastes harbor a wide range of pathogenic and indicator organisms. The composition in pathogens depends on the type of waste studied. A total of 109 bacteria were identified from sewage sludge, biowaste and bioslurry samples, which belong to 12 genera. Dudley et al. (1980); Strauch (1991); Carrington (2001); Lepeuple (2004) and Sahlström et al. (2008) have reported similar genera of bacteria from the sewage sludge and biowaste.

A total of 49 environmental isolates of 5 genera were taken for antibiotic susceptibility test against different antibiotics. Escherichia coli and faecal Streptococci are the indicator organisms and they were frequently isolated even from the digested residues (bio-slurry). While other bacteria such as Salmonella spp., Pseudomonas spp. and Staphylococcus spp. are pathogenic and most commonly associated with humans diseases. The selection of antibiotics for their susceptibility test was dependent upon the type of antibiotics used for the particular type of bacteria. The increasing use of antibiotics in humans, animals and agriculture may be the important factor in developing the antibiotic resistant bacteria. The antibiotic susceptibility pattern among
11 Escherichia coli isolates showed that $90.91 \%$ the isolates were resistant towards at least one of the antibiotics used and $45.46 \%$ of the total isolates were multidrug resistant. All isolates were sensitive to Gentamicin, Amikacin and Ceftazidime and the higher resistance was seen to Amoxycillin (90.91\%). The antibiotic resistance patterns obtained by Lin et al. (2004) among 113 enteric bacteria isolated from Mhlathuze river showed that $94.7 \%$ were resistant to at least one class of antibiotic, $75.2 \%$ were multiresistant and all isolates were sensitive to Gentamicin. Similarly, the study conducted by Alhaj et al. (2007) found that $61.2 \%$ of the total environmental isolates of $E$. coli were multi resistant. The lower percentage of multidrug resistant $E$. coli found in present study may be affected by the location (Pillai et al., 1997).

Among 12 environmental Pseudomonas aeruginosa isolates, $75 \%$ were found to be the multidrug resistant while $22.22 \%$ were resistant towards more than 3 antibiotics of different class. The higher susceptibility was observed to Amikacin and Gentamicin which exhibited $91.67 \%$ followed by Ciprofloxacin (83.34) and Ceftazidime $(66.67 \%)$ and all isolates were resistant towards Tetracycline and Cephalexin. Shahid and Malik (2005) reported that 96\% of clinical Pseudomonas aeruginosa isolates was multi drug-resistant and the majority (71.4\%) were resistant to 5 or more antibiotics. The clinical Pseudomonas aeruginosa isolates are more resistant to the antibiotics than environmental isolates (Shahid and Malik, 2005). 40\% of the isolates of Salmonella spp. were multidrug resistant (MDR), the higher resistance was 
R.C. Poudel, D.R. Joshi, N.R. Dhakal and A.B. Karki / Our Nature (2009) 7: 151-157

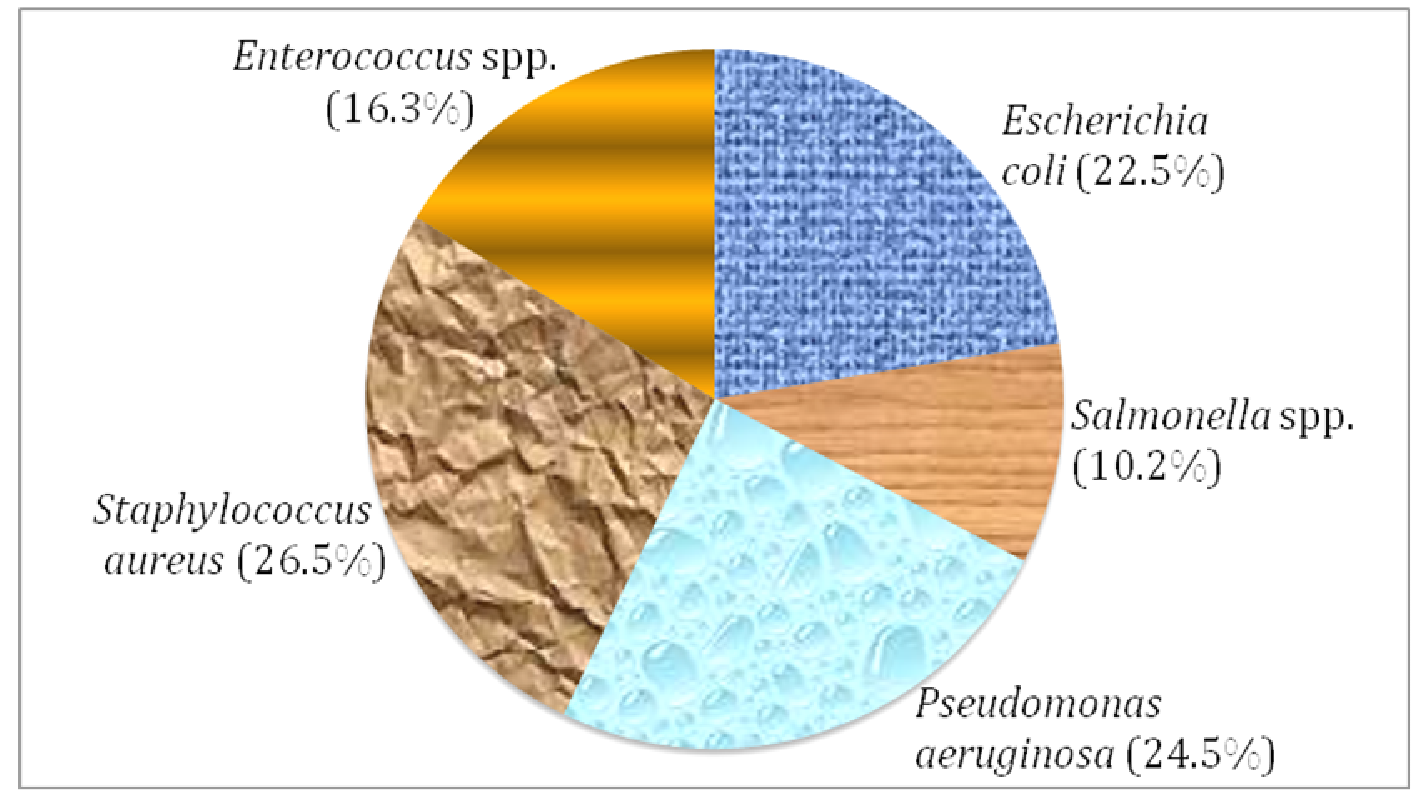

Figure 1. Distribution of bacterial isolates

Table 1. Antibiotic sensitivity pattern of Gram negative bacteria

\begin{tabular}{llllllllll}
\hline \multirow{2}{*}{$\begin{array}{l}\text { Antibiotics } \\
\text { used }\end{array}$} & \multicolumn{3}{c}{ E. coli $(\mathbf{1 1})$} & \multicolumn{3}{c}{ P.aeruginosa (12) } & \multicolumn{3}{c}{ Salmonella spp. (5) } \\
\cline { 2 - 9 } & S(\%) & PS(\%) & R(\%) & S(\%) & PS(\%) & R(\%) & S(\%) & PS(\%) & R(\%) \\
\hline Am & 9.1 & - & 90.9 & - & - & - & 20.0 & - & 80.0 \\
Cp & - & - & - & - & - & 100.0 & - & - & - \\
Ci & - & - & - & 58.3 & 33.3 & 8.4 & - & - & - \\
Cfx & - & - & - & - & - & - & 40.0 & 20.0 & 40.0 \\
Ca & 100.0 & - & - & 66.7 & 8.3 & 25.0 & - & - & - \\
Ak & 100.0 & - & - & 91.7 & - & 8.3 & - & - & - \\
G & 100.0 & - & - & 91.7 & - & 8.3 & 80.0 & 20.0 & - \\
T & 45.4 & 27.3 & 27.3 & - & - & 100.0 & 20.0 & 20.0 & 60.0 \\
C & - & - & - & - & - & - & 80.0 & - & 20.0 \\
Cf & 54.5 & 18.2 & 27.3 & 83.3 & - & 16.7 & 80.0 & - & 20.0 \\
Nf & 72.7 & 18.2 & 9.1 & - & - & - & - & - & - \\
Co & 72.7 & 18.2 & 9.1 & 16.7 & 8.3 & 75.0 & 80.0 & - & 20.0 \\
Na & - & - & - & - & - & - & 40.0 & 20.0 & 40.0 \\
\hline
\end{tabular}

$\mathrm{S}=$ Sensitivity, $\mathrm{PS}=$ Partially Sensitive, $\mathrm{R}=$ Resistance, $\mathrm{Am}=$ Amoxycillin, $\mathrm{Cp}=$ Cephalexin, $\mathrm{Ci}=\mathrm{Ceftriaxone}$, $\mathrm{Cfx}=$ Cefixime, $\mathrm{Ca}=$ Ceftazidime, $\mathrm{Ak}=$ Amikacin, $\mathrm{G}=$ Gentamicin, $\mathrm{T}=$ Tetracycline, $\mathrm{C}=$ Chloramphenicol, $\mathrm{Cf}=$ Ciprofloxacin, $\mathrm{Nf}=$ Nitrofurantoin, $\mathrm{Co}=$ Cotrimoxazole, $\mathrm{Na}=$ Nalidixic acid

Table 2. Antibiotic sensitivity pattern of Gram positive bacteria

\begin{tabular}{llllllll}
\hline $\begin{array}{l}\text { Antibiotics } \\
\text { used }\end{array}$ & \multicolumn{3}{c}{ Staphylococcus aureus (13) } & \multicolumn{3}{c}{ Enterococcus spp. (8) } \\
\cline { 2 - 7 } & S(\%) & PS $(\%)$ & R(\%) & MRSA & S(\%) & PS $(\%)$ & R(\%) \\
\hline
\end{tabular}


R.C. Poudel, D.R. Joshi, N.R. Dhakal and A.B. Karki / Our Nature (2009) 7: 151-157

\begin{tabular}{|c|c|c|c|c|c|c|c|}
\hline Am & 30.8 & - & 69.2 & & 75.0 & 12.5 & 12.5 \\
\hline $\mathrm{Cx}$ & 38.5 & - & 61.5 & & - & - & - \\
\hline Ox & 61.5 & - & 38.5 & & - & - & - \\
\hline M & 53.8 & 7.7 & 38.5 & & - & - & - \\
\hline $\mathrm{Cp}$ & - & - & - & & - & - & 100.0 \\
\hline $\mathrm{Ca}$ & 38.5 & - & 61.5 & $38.5 \%$ & - & - & 100.0 \\
\hline E & 61.5 & 15.4 & 23.1 & & 100.0 & - & - \\
\hline $\mathrm{T}$ & 100.0 & - & - & & 75.0 & - & 25.0 \\
\hline $\mathrm{Cf}$ & - & - & - & & 75.0 & 25.0 & - \\
\hline $\mathrm{Co}$ & 84.6 & 7.69 & 7.69 & & 50.0 & 12.5 & 37.5 \\
\hline $\mathrm{Va}$ & 100.0 & - & - & & 100.0 & - & - \\
\hline
\end{tabular}

$\mathrm{S}=$ Sensitivity, $\mathrm{PS}=$ Partially Sensitive, $\mathrm{R}=$ Resistance, $\mathrm{Am}=$ Amoxycillin, $\mathrm{Cx}=\mathrm{Cloxacillin}, \mathrm{Ox}=\mathrm{Oxacillin}, \mathrm{M}=$ Methicillin, $\mathrm{Cp}=$ Cephalexin, $\mathrm{Ca}=$ Ceftazidime, $\mathrm{E}=$ Erythromycin, $\mathrm{T}=$ Tetracycline, $\mathrm{Cf}=$ Ciprofloxacin, $\mathrm{Co}=$ Cotrimoxazole, $\mathrm{Va}=$ Vancomycin and MRSA= Methicillin resistant Staphylococcus aureus

Table 3. Antibiotic sensitivity pattern of MDR isolates

\begin{tabular}{|c|c|c|c|c|}
\hline \multirow[b]{2}{*}{ Bacteria } & \multicolumn{3}{|c|}{ No. of isolates resistance to } & \multirow{2}{*}{$\begin{array}{l}\text { Total MDR } \\
\text { isolates } \\
\text { No. }(\%)\end{array}$} \\
\hline & $\begin{array}{l}2 \text { drugs of } \\
\text { different class }\end{array}$ & $\begin{array}{l}\text { 3 drugs of } \\
\text { different class }\end{array}$ & $\begin{array}{l}>3 \text { drugs of } \\
\text { different class }\end{array}$ & \\
\hline Escherichia coli $(\mathrm{n}=11)$ & $\overline{4}$ & 1 & - & $5(45.5)$ \\
\hline P. aeruginosa $(\mathrm{n}=12)$ & 3 & 4 & 2 & $9(75.0)$ \\
\hline Salmonella spp. $(\mathrm{n}=5)$ & 1 & - & 1 & $2(40.0)$ \\
\hline S. aureus $(\mathrm{n}=13)$ & 2 & 1 & - & $3(23.1)$ \\
\hline Enterococcus $\mathrm{spp} .(\mathrm{n}=8)$ & 3 & 1 & - & $4(50.0)$ \\
\hline Total $(\mathrm{N}=49)$ & 13 & 7 & 3 & $23(46.9)$ \\
\hline
\end{tabular}

observed for Amoxycillin (80\%) followed by Tetracycline (60\%). Sahlström (2006) reported that among 101 Salmonella spp. isolated from sewage sludge, $12 \%$ of the strains were resistant to one or more antibiotics and $7 \%$ were multiresistant (resistant to $\geq 3$ antimicrobials). Similarly, among 33 strains of Salmonella spp. isolated from raw sewage sludge, 4 strains i.e. $12 \%$ were found to be multiresistant to the antibiotics used (MAF, 2003). A higher percentage of MDR Salmonella spp. in this study may be due to low number of the isolates and also due to defining MDR to those isolates that were resistant to $\geq 2$ antibiotics.

In this study, $23.07 \%$ of the total 13 Staphylococcus aureus isolates were multidrug resistant while MSSA (61.54\%) and MRSA (38.46\%). All the isolates were sensitive towards Vancomycin and Tetracycline. However, higher resistance was noted for Amoxycillin (69.23\%), followed by Cloxacillin and Ceftazidime (61.54\%). Communicable Diseases Intelligence reported among 524 clinical isolates of S. aureus, 417 (79.6\%) MSSA, 107 (20.4\%) MRSA and also found all 
MRSA isolates were sensitive to Tetracycline and Co-trimoxazole. $\mathrm{MOH}$ (2002) defined $S$. aureus as MRSA if the bacterium is resistant to oxacillin or methicillin but recommended Oxacillin unless a particular MRSA strain is shown to be more readily detected with methicillin. In this study, S. aureus resistant to Oxacillin were considered as MRSA but $S$. aureus isolates resistant to Oxacillin were also found to be resistant to Methicillin. 50\% isolates of Enterococcus spp. were found to

be MDR-strains and all the isolates were found to be sensitive towards Erythromycin and Vancomycin while $75 \%$ of the total isolates were sensitive towards Amoxycillin, Ciprofloxacin and Tetracycline. Similarly, all the isolates were resistance to Cephalexin and Ceftazidime.

\section{Conclusion}

Most of sewage sludge and biowaste isolates were found multidrug resistant. Therefore, it is important to manage the multidrug resistant bacteria present in sewage sludge and biowaste through the treatment to protect the human and animal health.

\section{Acknowledgements}

The authors express their sincere gratitude to National College, Kathmandu for providing the laboratory facilities. We are very grateful to Mr. Rajdeep Bomjan for his kind cooperation during the laboratory works.

\section{References}

Alhaj, N., N.S. Mariana, A.R. Raha and Z. Ishak 2007. Prevalence of antibiotic resistance among
Escherichia coli from different sources in Malaysia. Intn. J.Poultry Sci. 6(4): 293-297.

Andersson, D.I. 2003. Persistence of antibiotic resistant bacteria. Current Opinion in Microbiology 6: 452-456.

Baquero, F., M.C. Negri, M.I. Morosini and Blazquez, J. 1998. Antibiotic- selective environments. Clincal Infectious Disease 27: 55-61.

Benatti, C.T., C.R.G. Tavares, B.P.D. Filho and Md. L.R. Moitinho 2002. Operation of a slow rate anaerobic digester treating Municipal secondary sludge. Electron. J. Biotechnol. 5(3) ISSN: 07173458.

Carrington, E.G. 2001. Evaluation of sludge treatments for pathogen reduction -Final report. WRc Ref: CO 5026/1, European Communities.

Dahal, R.K., J. Koirala, P. Khadka, B.M. Pokhrel and N.R. Tuladhar 2005. The status of multidrug resistant and extended spectrum B-lactamase producing Salmonella isolated from blood culture. J. Nep. Assoc. Med. Lab. Sci. 7: 24-29.

Dudley, D.J., M.N. Guentzel, M.J. Ibarra, B.E. Moore and B.P. Sagik 1980. Enumeration of potentially pathogenic bacteria from sewage sludges. Appl. Environ. Microbiol. 39(1): 118-126.

Food Safety 2008. Food safety implications of landspreading agricultural, municipal and industrial organic materials on agricultural land used for food production in Ireland. Food Safety Authority of Ireland Publishers. ISBN-1-904465-59-5.

Halling-Sorensen, B., S. Nors Nielsen, P.F. Lanzky, F. Ingerslev, H.C. Holten Lutzhoft and G. Jorgensen 1998. Occurrence, fate and effect of pharmaceutical substances in the environment- A review. Chemosphere 36(2): 357-393.

Lepeuple, A.S., G. Gaval, M. Jovic and M.R. de Roubin 2004. Literature review on levels of pathogens and their abatement in sludges, soil and treated biowaste. Horizontal Project.

Lin, J., P.T. Biyela and T. Puckree 2004. Antibiotic resistance profiles of environmental isoaltes from Mhlathuze river, KwaZulu-Natal (RSA). Water SA 30(1): 22-28

Marchaim, U. 2007. Biogas processes for sustainable development. http://www.fao.org/docrep, Food and Agriculture Organization.

Ministry of Agriculture and Foresty 2003. Sewage sludge and sludge products for agricultural use $-A$ study on hygenic quality- Review (Ed. A. 
R.C. Poudel, D.R. Joshi, N.R. Dhakal and A.B. Karki / Our Nature (2009) 7: 151-157

Vuorinen). ISBN 952-453-113-5.

Ministry of Health 2002. Guidelines for the control of methicillin-resistant Staphylococcus aureus in New Zealand. Ministry of Health Publishers. ISBN 0478-27067-4.

Pillai, S.D., K.W. Widmer, K.G. Maciorowski, and S.C. Ricke 1997. Antibiotic resistance profiles of Escherichia coli isolated from rural and urban environments. J. Environ. Health., Part A. 32: 1665.

Sahlström, L. 2006. Recycled biowaste as a source of infection. Department of Biomedical Sciences and Veterinary Public Health, Swedish University of Agricultural Sciences, Uppsala. (Ph.D. Thesis)

Sahlström, L., E. Bagge, E. Emmoth, A. Holmqvist, M.L. Danielsson-Tham and A. Albihn 2008. A laboratory study of survival of selected microorganisms after heat treatment of biowaste used in biogas plants. Bioresource Technology 99: 7859-7865.

Savas, L., N. Duran, Y. Onlen, N. Savas and M. Erayman 2005. Prospective analysis of antibiotic susceptibility patterns of MRSA in a Turkish University Hospital. Turk. J. Med. Sci. 35: 323327.

Shahid, M. and A. Malik 2005. Resistance due to Aminoglycoside Modifying Enzymes in Pseudomonas aeruginosa isolates from burns patients. Ind. J. Med. Res. 122: 324-329.

Strauch, D. 1991. Survival of pathogenic microorganisms and parasites in excreta, manure and sewage sludge. Rev. Sci. Tech. Off. Int. Epiz. 10(3): 813-846. 